\title{
Burns from e-cigarettes and other electronic nicotine delivery systems
}

\author{
An emerging concern that needs a clinical, public health, and regulatory response
}

\author{
Clare Meernik researcher ${ }^{1}$, Felicia N Williams surgeon ${ }^{2}$, Bruce A Cairns director ${ }^{2}$, Ernest J Grant \\ nurse clinician $^{2}$, Adam $O$ Goldstein physician ${ }^{13}$
}

${ }^{1}$ Department of Family Medicine, University of North Carolina at Chapel Hill, Chapel Hill, NC 27599, USA; ${ }^{2}$ North Carolina Jaycee Burn Center,

Chapel Hill, NC, 27599, USA; ${ }^{3}$ Lineberger Comprehensive Cancer Center, University of North Carolina at Chapel Hill, Chapel Hill, NC, 27599, USA

With increasing use of electronic cigarettes (e-cigarettes) and other electronic nicotine delivery systems (ENDS) globally, the debate surrounding the potential harms or benefits may shift to ensuring that the devices are manufactured, marketed, and sold according to standards that reduce harm and promote health. Burns from overheating or explosions of ENDS are an emerging and under-researched concern. In light of the recent ruling that grants the US Food and Drug Administration authority to regulate ENDS ${ }^{1}$ and as their use becomes widespread worldwide, a clinical, public health, and regulatory framework to reduce ENDS related burns is needed.

Although the full scope of clinical burns and injuries from overheating or explosion of ENDS remains unknown, incidents reported to federal agencies, media outlets, and case reports seem to be increasing. ${ }^{2-4}$ Explosions can occur while the devices are being carried, resulting in serious bodily burns; explosions occurring during vaping can result in serious facial burns, facial and neck fractures, and loss of teeth. ${ }^{3}$ For ENDS users on oxygen therapy, such as patients with chronic obstructive pulmonary disease, the consequences can be fatal if the device catches fire and ignites oxygen equipment. ${ }^{5}$

\section{Better surveillance}

Accurately assessing the rise in ENDS related burns-and acquiring baseline data by which to measure future safety improvements-is difficult because no adequate surveillance system exists within the US or internationally. While the US FDA Safety Reporting Portal includes forms to report safety and health concerns from tobacco products, ${ }^{6}$ this voluntary system is insufficient and severely under-reports injuries related to e-cigarettes and ENDS. Most published data have identified incidents primarily through media reports. ${ }^{2-4}$ For instance, the US National Fire Protection Association identified just 15 e-cigarette related fires and explosions in the US in $2015,{ }^{3}$ but personal communication from members of the American Burn Association's burn prevention committee suggests that there were probably several hundred injuries in 2015 in the US.
Similar case numbers may be seen for 2016 as our burn center alone treated 10 patients presenting with severe burns and facial fractures from e-cigarette explosions in the first six months of 2016.

Current surveillance efforts are not working, and modifications are urgently required. We might learn from the reporting approaches used for other products, such as dietary supplements, which use multiple surveillance systems to track related adverse events. ${ }^{7}$ In the US, surveillance of ENDS might combine reports from the FDA Safety Reporting Portal—which may include reports from members of the public involved in minor incidents treated at home-with reports from burn centers and media outlets. Public health and burn experts with experience in ENDS injuries should collaborate to agree on protocols for collecting, coordinating, and disseminating surveillance data on such injuries and develop ENDS specific codes for burns that result in hospital admission as well as those treated in outpatient facilities. Other adverse event reporting systems, such as the Yellow Card system in the UK, can provide a system of analogous surveillance internationally. ${ }^{8}$

\section{Better regulation}

In August 2016, the FDA finalized rules to extend its authority to include the regulation of e-cigarettes and other ENDS. ${ }^{1}$ That authority can now focus on improving product design and manufacturing standards, with the explicit aim of reducing the risk of burns from these products. Improved safety

standards - similar to those enacted for childproof packaging of liquid nicotine after a rise in calls to poison centers related to use of e-cigarettes ${ }^{9}$ - will almost certainly reduce burns. Though some manufacturers may already be taking steps to prevent overheating and explosion, with thousands of brands and hundreds of manufacturers, mandatory oversight and industry-wide standards are long overdue. For instance, though standards for lithium ion batteries have been developed in the US, no standards have yet been specifically applied to lithium 
batteries in ENDS. The European Union already has legislation governing the safety of ENDS batteries,${ }^{10}$ and several products have been recalled in the past few years because of lack of compliance that could result in overheating or explosion. ${ }^{11}$ The revised EU Tobacco Products Directive, effective May 2016, mandates that e-cigarette producers establish and maintain data on suspected adverse health effects, further enhancing quality and safety oversight. ${ }^{12}$

Finally, consumers could be much better educated about the proper safe use of these devices (for example, the importance of using the correct charger), and the onus is on national and international regulatory authorities to require manufacturers to provide clear instructions about safe use, accompanied by stronger warnings. In one analysis of 12 e-cigarettes from nine manufacturers, no products warned consumers of the potential for overheating, explosions, or related injuries, and two products even claimed to be non-flammable. ${ }^{13}$

Given the lack of adequate surveillance, and increases in anecdotal reporting, it seems highly likely that the burden of injuries associated with ENDS has been underestimated. Better surveillance, tighter regulation, and improved information for consumers should be priorities for all agencies concerned with product safety and protecting the public.

Competing interests: We have read and understood BMJ policy on declaration of interests and have no relevant interests to declare.

Provenance and peer review: Not commissioned, externally peer reviewed.
1 Department of Health and Human Services, Food and Drug Administration. Deeming tobacco products to be subject to the Federal Food, Drug, and Cosmetic Act, as amended by the Family Smoking Prevention and Tobacco Control Act; Restrictions on the sale and distribution of tobacco products and required warning statements for tobacco products. 2016. https://federalregister.gov/a/2016-10685

2 Rudy SF, Durmowicz EL. Electronic nicotine delivery systems: overheating, fires and explosions. Tob Control 2016 Mar 9. [Epub ahead of print.] doi:10.1136/tobaccocontrol2015-052626.. pmid:26962042.

3 Campbell R. National Fire Protection Association, fire analysis and research division. Electronic cigarette explosions and fires: the 2015 experience. 2016. http://www.nfpa.org/ research/reports-and-statistics/fire-causes/electrical-and-consumer-electronics/electroniccigarette-explosions-and-fires-the-2015-experience

4 United States Department of Homeland Security, Federal Emergency Management Administration, United States Fire Administration (USFA). Electronic cigarette fires and explosions. Oct 2014. https://www.usfa.fema.gov/downloads/pdf/publications/electronic cigarettes.pdf

5 Man killed as e-cigarette "explodes", Merseyside fire service says. BBC News 8, 2014 Aug 8. http://www.bbc.com/news/uk-england-merseyside-28701515

6 FDA SRP

7 Gardiner P, Sarma DN, Low Dog T, et al. The state of dietary supplement adverse event reporting in the United States. Pharmacoepidemiol Drug Saf2008;17:962-70. doi:10.1002 pds. 1627 pmid: 18613260 .

8 UK yellow card scheme. https://yellowcard.mhra.gov.uk/.

9 Kamboj A, Spiller HA, Casavant MJ, Chounthirath T, Smith GA. Pediatric exposure to ENDS, nicotine, and tobacco products in the United States. Pediatrics 2016. [Epub ahead ofprint.] doi:10.1542/peds.2016-0041

10 Action on Smoking and Health. The impact of the EU Tobacco Products Directive on e-cigarette regulation in the UK. 2016.http://www.ash.org.uk/files/documents/ASH_1011. pdf

11 European Commission. Rapid alert system for dangerous non-food products. http://ec. europa.eu/consumers/consumers_safety/safety_products/rapex/alerts/main/?event=main search\#searchresults

12 The Tobacco and Related Products Regulations. 2016. http://www.legislation.gov.uk/ uksi/2016/507/made

13 Yang L, Rudy SF, Cheng JM, Durmowicz EL. Electronic cigarettes: incorporating human factors engineering into risk assessments. Tob Control 2014;23(Suppl 2):ii47-53. doi:10. 1136/tobaccocontrol-2013-051479 pmid:24732164.

Published by the BMJ Publishing Group Limited. For permission to use (where not already granted under a licence) please go to http://group.bmj.com/group/rights-licensing/ permissions 